\title{
Analysis on the Causes of the Erecting Fault - Wide Concrete Continuous Bridge by Short Line Method
}

\author{
Xing-Fa WU ${ }^{1, a}$, Yue HUANG ${ }^{2, b^{*}}$ \\ ${ }^{1}$ No.11 Jinyinhu Road, Dongxihu District, Wuhan City, 430040, PRC \\ ${ }^{2}$ Key Lab of Large-span Bridge Construction Technology, Ministry of Communication, PRC Hubei \\ Wuhan 430040 \\ awuxingfa@live.com, bhuangyue1029@163.com \\ ${ }^{*}$ Corresponding author
}

Keywords: Short-line Method, Erecting Fault, Continuous Gird Bridge, Causes Analysis.

\begin{abstract}
This paper based on Quanzhou bay cross-sea bridge. Quanzhou Bay Bridge Northern Approach, width $20 \mathrm{~m}$, was erected with the "T" structure cantilever assembly method. "T" configuration closure may occur Faulting phenomena. Analysts predict that the weight of precast segments, inelastic deformation of segments, pier top block mounting accuracy, wiping glue thickness between segments of the cantilever beam greatly affected the maximum elevation. In addition, temperature effect, the main beam material properties, asymmetric temporary load also have some impact on the maximum cantilever state. Effective measures should be taken to eliminate the error.
\end{abstract}

\section{Introduction}

This paper based on Quanzhou bay cross-sea bridge, span arrangement for which is $5 \times 70 \mathrm{~m}$ (as Fig.1), with double cell box girder cross-section (Fig.2). The precast concrete box girders and cast-in-situ diaphragm beam, are using durable marine engineering concrete and constructed with the method of short segmental precast and prestressed assembly.

Fig. 1 Span Arrangement

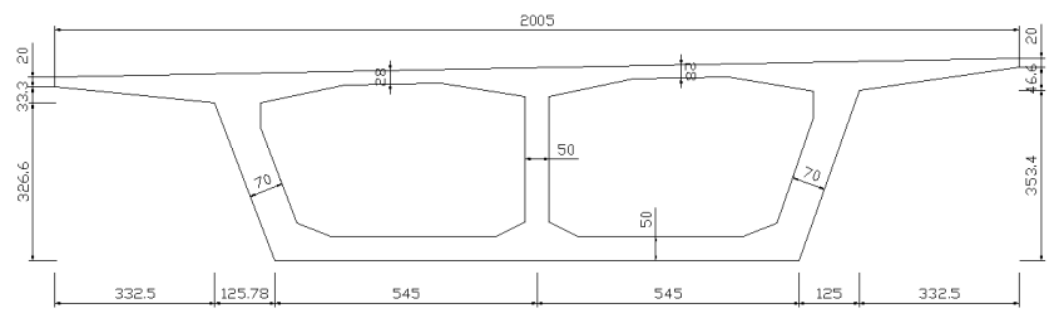

Fig. 2 Cross-section

The segment of the bridge were prefabricated in a factory, and the segment length is $2 \mathrm{~m}, 2.8 \mathrm{~m}$, $3.1 \mathrm{~m}, 3.5 \mathrm{~m}, 3.6 \mathrm{~m}$, etc. The maximum lifting weight is $187.9 \mathrm{t}$. After the precasting, the segment were transported to the construction site and installed with cantilever construction (Fig.3).

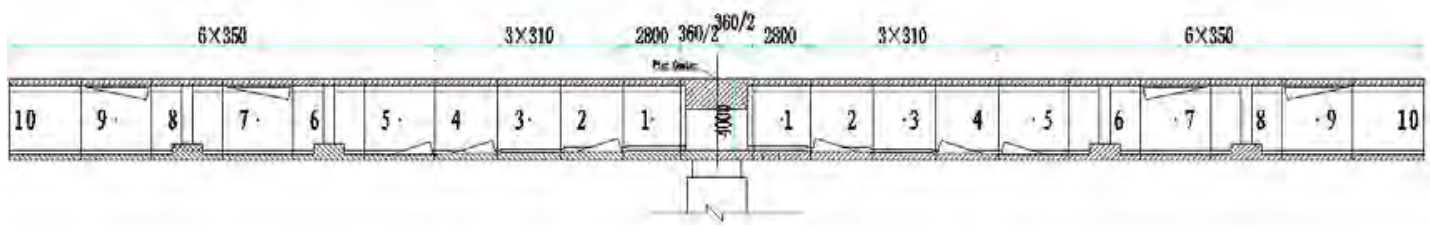

Fig. 3 Cantilever Construction 
After the pier top block was installed, bridge machine was mounted on the top block; then erecting machine symmetric lifting beams of the middle, then wiping the epoxy glue between segments; tensioning temporarily prestress, after the hardening of epoxy glue, permanently tensioned prestress. Repeat the above steps to complete installation of all cantilever block; finally pouring wet joints, tension closure beam cross-sections to complete an entire girder installation. Repeat the above steps can be completed for all " $\mathrm{T}$ " structure of the cantilever erection. Because each step in the installation process may differ from the actual state of both the state and the theoretical installation, a certain degree of Faulting may occur to both sides of the closure. This paper studies the reasons of the faults.

\section{Faulting Causes and Analysis}

In the installation process of the segments of the beam, individual " $\mathrm{T}$ " and " $\mathrm{T}$ " configurations closure structure Faulting $(1 \sim 3 \mathrm{~cm})$ phenomenon were found. many reasons may lead to formation of faulting, the prefabricated stage, the installation phase, etc. After generating Faulting, forced closure of the will have an impact on the structure; understand fault reasons so that we can effectively reduce the Faulting.

During the Prefabricating, we make adjustments to the axis errors, but because of the system or the level of construction is relatively low level, pre-generated error can not be completely eliminated in the latter; " $\mathrm{T}$ " configuration error while the last piece of the beam resulting make the elimination impossible, it would be cumulated to the installation stage.

The installation process, for many changes in the field installation conditions, the theoretical analysis often leads to inconsistent results and the actual results, so the installation process and the expected effect of the deformation structures are different. The main Factors are: structural dimensions, material modulus, tensile force tendons, ambient temperature, construction and installation of precision theoretical calculations there are some differences.

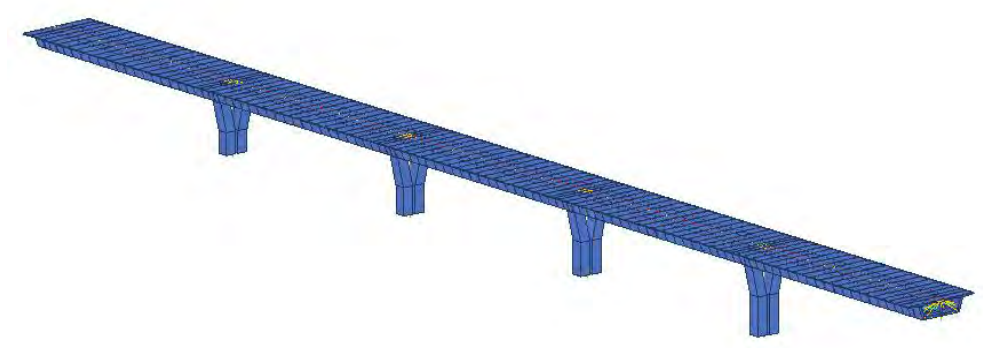

Fig. 4 Finite Element Model

This paper analyzes by calculating the impact of various factors on the "T" cantilever structure with cantilever erection, that impact on the state's closure. Using the finite element calculation software TDV RM2006 (Fig.4), we analyzed and calculated the "T" structure under different circumstances.

\section{Affect of the Accuracy of the Pier Top Block Installation}

To install a " $T$ " configuration, firstly we need to install the pier top block, accurate positioning was adopted, then the tendons and other measures will be used to fix the top pier block (Fig.5). In the adjusting of the elevation of the top block pier, for various reasons, the final outcome and the theoretical requirement makes some difference. Subsequent segments of the installation, are affected by matching to the pier top block. It is assumed that after the top of the pier blocks properly installed, the axial direction of the front and rear elevation measuring point error of $1 \mathrm{~mm}$ (Fig.6), measured pitch pier center $1.45 \mathrm{~m}$, bridge span $70 \mathrm{~m}$, " $\mathrm{T}$ " configuration closure wet seam $20 \mathrm{~cm}$, so the cantilever elevation deviation caused by pier top block with the theoretical difference is: 
Due to precision of measuring instruments and harsh winds environmental impact, pier top block construction accuracy of $1 \mathrm{~mm}$ error is very common, so pier top block deviation on $\mathrm{T}$ largest the cantilever structure is very large elevation.

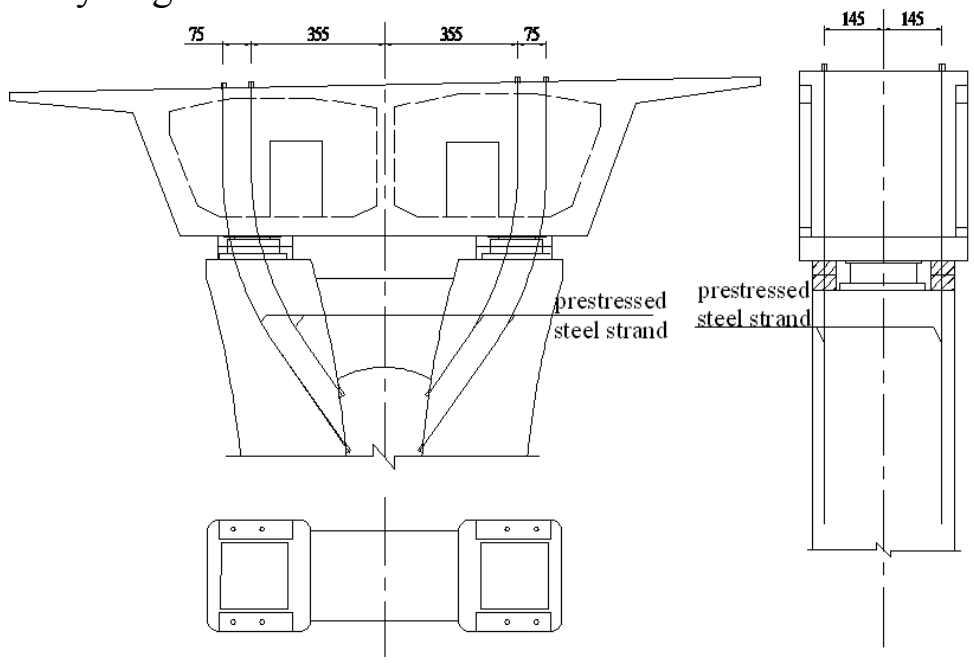

Fig. 5 Pier Top Block Anchorage

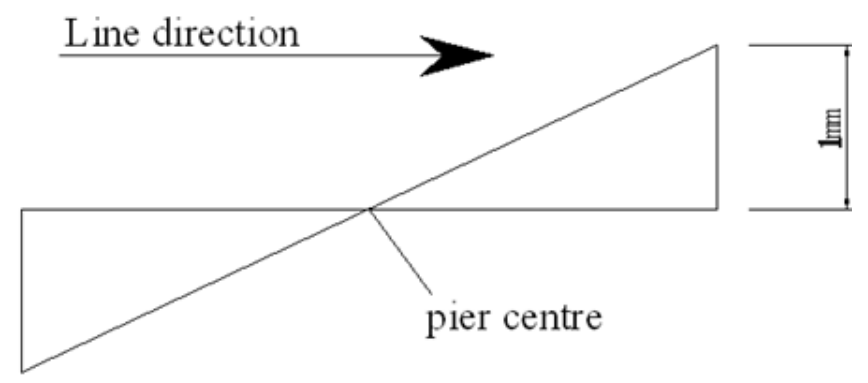

Fig. 6 Pier Top Block Displacement

Table 1 shows the comparison of the Pier block of Qanzhou Bay bridge, where the secondary cast is top block horizontal beam pier pouring. 1,3,2, 4, respectively, are the front and rear points. As can be seen from the table, after the overall elevation, error of the front and rear points elevation measurement point in the secondary cast (not the subsequent segments installed) is $2 \mathrm{~mm}$ (as shown in Table 1), which consistent with the above calculation analysis of the situation. In addition, top of the block overall elevation or reduce would impact the maximum height of the cantilever end the "T" structure little, and this article will not take particularly calculation.

Tab. 1 Elevation of a Pier Top Block Box Girder

\begin{tabular}{|c|c|c|c|c|c|c|c|c|c|c|c|c|}
\hline & \multirow{2}{*}{$\begin{array}{c}\text { Instruc } \\
\text { tion }\end{array}$} & \multicolumn{2}{|c|}{$\begin{array}{l}\text { Position } \\
\text { adjusting }\end{array}$} & \multicolumn{3}{|c|}{ Second cast } & \multicolumn{3}{|c|}{ Cross span } & \multicolumn{3}{|c|}{ Final } \\
\hline & & $\begin{array}{r}\text { Actual } \\
\text { value }\end{array}$ & $\begin{array}{l}\text { Err } \\
\text { or }\end{array}$ & $\begin{array}{l}\text { actual } \\
\text { value }\end{array}$ & $\begin{array}{l}\text { Load } \\
\text { error }\end{array}$ & $\begin{array}{l}\text { err } \\
\text { or }\end{array}$ & $\begin{array}{l}\text { Actual } \\
\text { value }\end{array}$ & $\begin{array}{l}\text { Load } \\
\text { error }\end{array}$ & $\begin{array}{l}\text { err } \\
\text { or }\end{array}$ & $\begin{array}{l}\text { Actual } \\
\text { value }\end{array}$ & $\begin{array}{l}\text { Load } \\
\text { error }\end{array}$ & $\begin{array}{l}\text { err } \\
\text { or }\end{array}$ \\
\hline 1 & 16.642 & 16.643 & 1 & 16.638 & -5 & -4 & 16.655 & 17 & 13 & 16.659 & 4 & 17 \\
\hline 2 & 16.483 & 16.485 & 2 & 16.48 & -5 & -3 & 16.494 & 14 & 11 & 16.495 & 1 & 12 \\
\hline 3 & 16.63 & 16.628 & -2 & 16.627 & -1 & -3 & 16.609 & -18 & -21 & 16.604 & -5 & -26 \\
\hline 4 & 16.463 & 16.46 & -3 & 16.455 & -5 & -8 & 16.439 & -16 & -24 & 16.438 & -1 & -25 \\
\hline
\end{tabular}




\section{Elevation Error Caused by Wiping Glue Thickness}

Segments match to segments, and after consideration of environmental corrosion and other factors we still need to wipe the surface of the match, after the hardening of epoxy glue permanently prestress was tensioned.

During the Construction monitoring process, it is found that the construction site generally use artificial means to wipe glue, so that the thickness id inevitably uneven (Fig.7); temporary tensioned prestressed sync will also cause uneven glue on thickness.

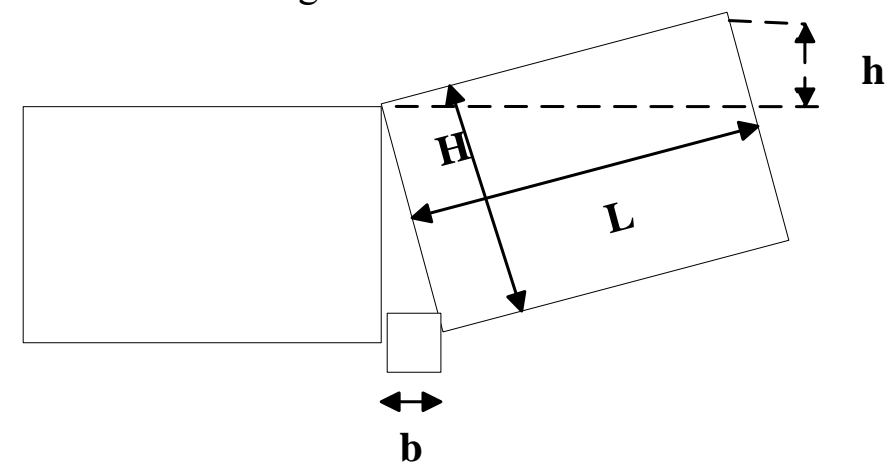

Fig.7 Calculation Principle of Elevation Changes

Suppose, in extreme cases, from the top block to the maximum cantilever 10 \# block, thickness of the glue between all segments of is uneven, and the thickness of the higher edge is thicker than the lower edge for $1 \mathrm{~mm}$, then the elevation error of the largest cantilever end is:

$$
\Delta \mathrm{H} 2=(33.1+30.3+27.2+24.1+21+17.5+14+10.5+7+3.5) \times 1 \mathrm{~mm} / 3.4=55.3 \mathrm{~mm}
$$

In the above formula, $1 \mathrm{~mm}$ i.e. diagram $\mathrm{b}$ (non-uniform thickness or thickness of the gasket plastic), $3.4 \mathrm{~m}$ for high beam; considering $\mathrm{b}$ minimal value, the parameters at FIG can be considered to meet formula:

$$
\frac{b}{H}=\frac{h}{L}
$$

then

$$
h=b L / H
$$

Because this study is considering the most extreme cases, the elevation error caused by uneven thickness of plastic will not up to the calculation of $55 \mathrm{~mm}$. Uniform glue thickness affects only the beam length, which is part of the error can usually be offset by considering the beam in precast segmental shortening and wet seams have enough surplus amount to eliminate some errors of beam length, so this article does not consider it.

\section{Influence of Segments Warping Caused by Storing}

After precasting beams on the prefabricating pedestal, the stock was moved to the pedestal to place when concrete strength got a certain value, generally is about 1 to 2 days from pouring concrete to move to keep beams pedestal; for various reasons beams keeping time is too short, or winter conservation is not proper, resulting in a certain deflection along the bridge, some of which caused by shrinkage and creep which is unrecoverable deformation. Site measurement showed an 
upward growth trend of error.
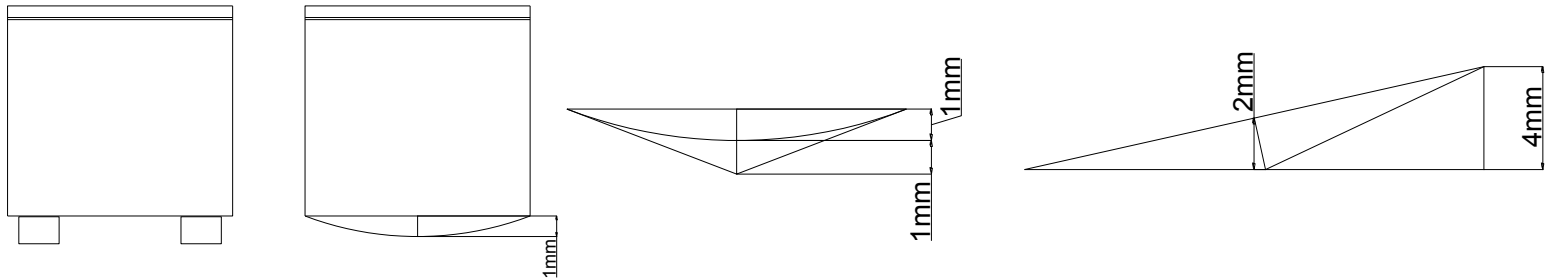

Fig. 8 Non-elastic Deformation

Block 1\# is now assumed that the central non-elastic deformation is $1 \mathrm{~mm}$ (Fig.8), since the deformation occurs with respect to the segment length is very small, it can happen that the upturned end sections of $4 \mathrm{~mm}$, the maximum error occurs in the cantilever end is:

$$
\Delta \mathrm{H} 2=-4 \mathrm{~mm} \times 33.1 / 2.8=-46.7 \mathrm{~mm}
$$

Extreme conditions were considered in this study, 1\# block inelastic deformation, the deformation of the segments on the maximum cantilever end elevation impact is very large by calculation, if this situation occurs to several segments, the elevation error will increases rapidly, and difficult to control.

The width of the Quanzhou bay bridge reaches $20 \mathrm{~m}$, inelastic deformation of segments may also lead to an overall torsional deformation; so that even when the axis of elevation of both sides are perfectly matched, there will still be scissors-type Faulting. Torsional deformation is extremely difficult to reverse, and it should be avoided that beam pivots deposit is not a in the same plane, the fulcrum should be exactly located on the same height.

\section{Other Factors}

\section{Asymmetric Temporary Loads on the Structure}

In the segments installation phase, there's some temporary loads placed on the bridge, construction machinery, steel wire, etc.; If they are not properly managed, items left unattended, may cause unreasonable maximum displacement of the cantilever end. Suppose the "T" structure is applied to $100 \mathrm{KN}$ force by one side of the biggest cantilever ends .Calculating by the model analysis, the maximum vertical displacement of the cantilever end is $4 \mathrm{~mm}$.

\section{Influence of Changes in the Elastic Modulus of the Structure}

Concrete is a great attribute discrete materials, all aspects of construction would impact the attribute of the concrete, such as the nature of raw materials, construction and temperature;. In order to clarify the elastic modulus affects on the largest the cantilever deflection, assuming the value difference of elastic modulus is $\pm 10 \%$, obtaining TDV model to calculate, the elevation change is only $\pm 0.4 \mathrm{~mm}$.

\section{Selfweight Influence on the Maximum Cantilevered End Elevation}

In prefabricated stage, if the template takes no long-term adjustment, they may be deformed. And this deformation effects are usually happens to not a single block, but one side of the structure of the entire "T". Furthermore, templates deformation is generally the expansion; so this calculation considering all segments on one side of $\mathrm{T}$ structure weight $5 \%$ more than the design value, then the maximum deflection of the cantilever end is $22 \mathrm{~mm}$.

\section{Installation Phase Gradient Temperature}

In installation phase, " $\mathrm{T}$ " configuration environment exposed to sunlight, the sunny surface and the back surface will be significant different. Temperature difference will cause some distortion in 
the structure of the largest cantilevered end. Beams calculated considering the temperature difference between the top and bottom beams were $1{ }^{\circ} \mathrm{C}$ and $10{ }^{\circ} \mathrm{C}$, then the maximum displacement of the cantilever beam ends were $1 \mathrm{~mm}$ and $9 \mathrm{~mm}$. Taking into account both "T" structure are in the same environment, the temperature gradient can be considered to form a small contribution to the fault; yet the the force of thestructure after closure is influented, so generally construction monitor would require lower temperatures while pouring wet seam.

\section{Elimination of Elevation Error}

As in Figure 6, an epoxy resin between the top or bottom edge of the two sections based on the formula (3) and (4) to adjust the elevation. If the prediction error of the elevation is positive, then add gasket at the upper edge; prestressed tension order adjustment may also make sense.

For example, When 5th pair of segments had been installed, the elevation error is shown in table 2: 1,2 point for the beam front elevation points; 3,4 point for the back-end elevation point, $\triangle \mathrm{Z}$ is the difference between the measured value and the theoretical value. If you do not take measures to adjustment, the axis error in 10th pair of segments would be up to $55 \mathrm{~mm}$,as shown in Formula 6.

$$
\Delta \mathrm{H}=20+((20+19) / 2-(18+17) / 2) \times 3.5 \times 5=55 \mathrm{~mm}
$$

When $3 \mathrm{~mm}$ gasket was set on top of segment, the axis error in 10th pair of segments would be drop to $2.5 \mathrm{~mm}$, as shown in formula 7 .

$\Delta \mathrm{H}=55-3 \times 3.5 \times 5=2.5 \mathrm{~mm}$

After $3 \mathrm{~mm}$ gasket was set on top of segment in 5th pair of segment ,the actual elevation error of 10th pair of segment is shown in table 2.

Actual project varies, and not all elevation error problems can be simply solved by adding a shim, sometimes you need to add shims between multiple segments, or with the use of other methods described above.

Tab. 2 Contrast of Elevation Error(mm)

\begin{tabular}{|c|c|c|c|c|c|}
\hline \multicolumn{2}{|c|}{ Points } & 1 & 2 & 3 & 4 \\
\hline \multirow{2}{*}{$\Delta \mathrm{H}(\mathrm{mm})$} & $5 \#$ & 20 & 19 & 18 & 17 \\
\cline { 2 - 6 } & $10 \#$ & 5 & 6 & 4 & 8 \\
\hline
\end{tabular}

\section{Summary}

Quanzhou Bay Bridge Northern Approach, single bridge width 20m, using the" $T$ " structure cantilever assembly construction process. "T" configuration closure may occur Faulting phenomena. Analysts predict that the weight of precast segments, inelastic deformation of segments, pier top block mounting accuracy, wiping glue thickness between segments of the cantilever beam greatly affected the maximum elevation. In addition, temperature effect, the main beam material properties, asymmetric temporary load also have some impact on the maximum cantilever state.

During construction of short-line method for continuous girder bridge, for the smooth closure, the following precautions:

(1) In the precast stage, instruction should be adjusted to eliminate the error; pouring concrete should use properly conservation, especially in cold seasons, and sufficient strength should be assured before moving to keep beam area. When the template is deformed, recalibrated immediately to eliminate distortion;

(2) Shall the beam-keep pedestal flat, all the force required to support in a same plane; 
(3) In the installation stage, the top pier block error should be minimized as much as possible;

(4) The glue must be uniform;

(5) Temporary load should be symmetrical on the top of the block and close to the pier top block.

\section{References}

[1]Yue Huang, Min Wang, Hehui Zheng: Journal of China\& The 2012 annual conference of the bridge. 536-540(2012-9) In Chinese.

[2]Min Wang, Yongtao Zhang, Jinghong Liu: Engineering Sciences. 79-81(2009-11) In Chinese.

[3]Yue Huang, Min Wang, Hehui Zheng, Xingfa Wu: Geometry Control Technology of Transition Curve Section in Cross-sea Bridge Erected by Precasting Segment Girder, 2nd International Conference on Civil Engineering and Transportation1548-1553(2012). 